\title{
Can integration reduce inequity in healthcare utilization? Evidence and hurdles in China
}

\author{
Miaomiao Zhao ${ }^{1,2+}$, Baohua Liu' ${ }^{1 \dagger}$, Linghan Shan ${ }^{1 \dagger}$, Cui Li ${ }^{1}$, Qunhong Wu ${ }^{1 *}$ D, Yanhua Hao ${ }^{1 *}$, Zhuo Chen ${ }^{3,4}$,
} Lan Lan', Zheng Kang ${ }^{1}$, Libo Liang ${ }^{1}$, Ning Ning ${ }^{1}$ and Mingli Jiao'

\begin{abstract}
Background: Integration of medical insurance schemes has been prioritized as one of the key strategies to address inequity in China's health system. The first pilot attempt to integrate started in 2003 and later expanded nationwide. This study aims to assess its intended impact on inequity in inpatient service utilization and identify the main determinants contributing to its ineffectiveness.

Methods: A total of 49,365 respondents in the pilot integrated area and 77,165 respondents in the non-integration area were extracted from the Fifth National Health Services Survey. A comparative analysis was conducted between two types of areas. We calculate a concentration index $(\mathrm{Cl})$ and horizontal inequity index $(\mathrm{HI})$ in inpatient service utilization and decompose the two indices.

Results: Insurance integration played a positive role in reducing inequality in inpatient service utilization to some extent. A 13.23\% lower in $\mathrm{HI}$, a decrease in unmet inpatient care and financial barriers to inpatient care in the pilot integrated area compared with the non-integration area; decomposition analysis showed that the Urban-Rural Residents Basic Medical Insurance, a type of integrated insurance, contributed 37.49\% to reducing inequality in inpatient service utilization. However, it still could not offset the strong negative effect of income and other insurance schemes that have increased inequality.

Conclusions: The earlier pilot attempt for integrating medical insurance was not enough to counteract the influence of factors which increased the inequality in inpatient service utilization. Further efforts to address the inequality should focus on widening access to financing, upgrading the risk pool, reducing gaps within and between insurance schemes, and providing broader chronic disease benefit packages. Social policies that target the needs of the poor with coordinated efforts from various levels and agencies of the government are urgently needed.
\end{abstract}

Keywords: Medical insurance integration, Inequity, Inequality, Inpatient service utilization

\section{Background}

Equity in healthcare is one of the most important priorities in any healthcare system [1]. The achievement of equal access to healthcare is regarded as a key element of health system performance and universal health coverage (UHC) $[2,3]$. Equity in healthcare utilization is

\footnotetext{
* Correspondence: wuqunhong@163.com; hyhyjw@126.com

${ }^{+}$Miaomiao Zhao, Baohua Liu and Linghan Shan contributed equally to this work and were co-first authors of the article.

'Department of Social Medicine, School of Health Management, Harbin

Medical University, 157 Baojian Road, Nangang District, Harbin 150086, Heilongjiang, China

Full list of author information is available at the end of the article
}

affected not only by an individual's socioeconomic status [4], but also by fragmentation in healthcare system [5]. Health insurance is one of the most important factors to improve equity in healthcare since it provides a safeguard against risks and barriers to healthcare especially for those who are suffering financial difficulty $[6,7]$. In many cases, developing countries are striving to achieve UHC quickly by combining multiple health insurance schemes covering different population groups into fewer or a unified insurance scheme [8]. Meanwhile, differences in government subsidies of the premium and benefit packages offered by the fragmented insurance

(c) The Author(s). 2019 Open Access This article is distributed under the terms of the Creative Commons Attribution 4.0 International License (http://creativecommons.org/licenses/by/4.0/), which permits unrestricted use, distribution, and reproduction in any medium, provided you give appropriate credit to the original author(s) and the source, provide a link to the Creative Commons license, and indicate if changes were made. The Creative Commons Public Domain Dedication waiver (http://creativecommons.org/publicdomain/zero/1.0/) applies to the data made available in this article, unless otherwise stated. 
scheme unexpectedly contribute to inequity in healthcare utilization across groups with different levels of wealth $[9,10]$. A study using data from nine developing countries shows the gap of healthcare utilization between the richest and the poorest ranged from 1.7 times to a surprising 12 times [11].

China achieved the goal of universal coverage of medical insurance swiftly by establishing multiple medical schemes. Since the introduction of social medical insurance in 1990s, insurance coverage gradually expanded. By 2011, about 95\% of the Chinese population was covered by a Social Basic Medical Insurance (SBMI) programme including the Urban Employee Basic Medical Insurance (UEBMI), the New Rural Cooperative Medical Scheme (NRCMS), and the Urban Resident Basic Medical Insurance (URBMI) [12]. This achievement is considered to be the first step toward UHC [13]. However, the SBMI system in China was highly segmented. The three schemes were separately administered and operated locally based on different eligibility requirements (employment status, urban and rural household registration) [14]. The UEBMI covered urban employees with the funds contributed from the employers and employees going into a collectively pooled account at the municipal level and an individual medical savings account. The NRCMS was a voluntary medical insurance program for rural residents, which was jointly funded by government subsidies and individual premiums at county-level. The URBMI was for urban residents who were not covered by the UEBMI or NRCMS, and the funds were pooled at the municipal-level with contributions from government subsidies and premiums. Therefore, more than 3000 funds operated independently in the three SBMI schemes [10]. The benefits package of services and medicines provided as well as reimbursement policy varied significantly among different insurance types, resulting in a rapid increase of inequity in healthcare utilization. Previous studies revealed a gap of 2.33 times in actual use of inpatient services between richest and poorest [15].

In order to address the inequity problem caused by the fragmented medical insurance system, the Chinese government selected several areas to launch pilot insurance integration reform since 2003. Two kinds of models emerged in the pilot areas. The one which merged the UEBMI, URBMI, and NRCMS into one uniform scheme called Uniform Social Basic Medical Insurance (USBMI). This model was adopted by several high-income cities such as Zhongshan and Dongguan [16, 17]. The other type of pilot only merged the URBMI and NRCMS and is called Urban-Rural Residents Basic Medical Insurance (URRBMI). URRBMI was adopted by most pilots because the financing source and level of contribution of the URBMI and NRCMS were roughly similar. Aspects including unifying enrollees, premiums, pooling level of fund, benefits packages, reimbursements arrangement, and fund management system were involved in reform [18]. With the health reform deepening and fragmentation more recognizable nationwide, Chinese government officially endorsed a nationwide policy for medical insurance integration in 2016 [19]. Currently, the national integration reform is still in its initial stage, facing many challenges because of the absence of national guideline. Thus it is timely and fills a critical need to conduct studies about the integration pilots.

Current studies on integration reform mainly focus on a theoretical policy analysis $[14,20]$, and the observational summary of the pilots' experience [21-23]. Some empirical research studied the willingness and satisfaction among enrollees towards integration [18, 24]. Equity in healthcare utilization is advocated as the core goal of integrated reform. However, there is no quantitative study so far that used national representative data to evaluate to what degree this objective has been achieved. Using inequity in inpatient service utilization as the main variable of interest, this study seeks to answer the following questions: how is the inequity in inpatient service utilization in the integrated area comparing with that in the non-integrated area? What is the impact of the insurance integration on inequity? What's the hurdle to implementing insurance integration and how to improve it? Our findings will provide evidential support for future policy development on insurance integration in China and offer lessons to countries that are facing similar challenges.

\section{Method}

\section{Data source}

The data was drawn from the Fifth National Health Services Survey (NHSS) in 2013. A multi-stage stratified cluster random sampling method was used and all the responses were self-reported. The NHSS covered 31 provinces with 156 sample areas (including nearly 300, 000 respondents from 93,600 households).

In NHSS, there were 10 provinces whose sample areas had both integration reform pilots and non-integrated areas; 22 pilot areas in these 10 provinces were grouped as the integration group (pilot integrated area) and the remaining 42 non-integrated areas were grouped as the reference group (non-integrated area). In addition, the integration group also include 3 provinces that underwent a total integration reform (therefore has no reference group), we chose 3 other provinces whose sample areas were all without integration reform but with similar social economic levels (per capita GDP) as their reference group. The features and differences of the medical insurance schemes in pilot integration area and non-integrated area are shown in Table 1. Finally, 49, 
Table 1 Comparison of the medical insurance schemes and its features and differences in integration area and non-integration area

\begin{tabular}{|c|c|c|c|}
\hline & \multicolumn{2}{|l|}{ integration pilot area } & \multirow[t]{2}{*}{ Non-integration area } \\
\hline & Model 1 & Model 2 & \\
\hline Specific arrangement & $\begin{array}{l}\text { Merged the three existing } \\
\text { insurance schemes (UEBMI, } \\
\text { URBMI and NRCMS) into a } \\
\text { new scheme--USBMI }\end{array}$ & $\begin{array}{l}\text { Only merged the URBMI and } \\
\text { NRCMS into a new scheme- } \\
\text { URRBMI, UEBMI was kept. }\end{array}$ & $\begin{array}{l}\text { The three existing insurance schemes still } \\
\text { run separately. }\end{array}$ \\
\hline Population coverage & USBMI covered all population & $\begin{array}{l}\text { URRBMI covered urban-rural } \\
\text { residents except for urban } \\
\text { employees. }\end{array}$ & $\begin{array}{l}\text { UEBMI covered urban employees, URBMI } \\
\text { covered urban residents, NRCMS covered } \\
\text { rural residents. }\end{array}$ \\
\hline Pooling level of fund & USBMI was pooled at municipal level. & $\begin{array}{l}\text { URRBMI were pooled at } \\
\text { municipal level. }\end{array}$ & $\begin{array}{l}\text { UEBMI and URBMI were pooled at } \\
\text { municipal level, while NRCMS was pooled } \\
\text { at county level. }\end{array}$ \\
\hline Contribution of premium & $\begin{array}{l}\text { All urban employees kept the } \\
\text { previous percentage of wage } \\
\text { for premium contribution } \\
\text { which was shared by employees } \\
\text { and employers; the remaining } \\
\text { urban and rural residents paid } \\
\text { the flat rate, which was also } \\
\text { shared by local government. }\end{array}$ & $\begin{array}{l}\text { In URRBMI, urban-rural residents } \\
\text { paid uniform flat rate and was } \\
\text { shared by individual and } \\
\text { government, which was } \\
\text { adjusted yearly; the premium } \\
\text { level of URRBMI were much } \\
\text { higher than un-integrated } \\
\text { insurance schemes. }\end{array}$ & $\begin{array}{l}\text { In UEBMI, employees paid percentage of } \\
\text { wage for premium contribution which } \\
\text { were shared by employees and employers; } \\
\text { In URBMI and NRCMS, residents paid the } \\
\text { flat rate, which was also shared by local } \\
\text { government; the premium level of URBMI } \\
\text { was higher than NRCMS }\end{array}$ \\
\hline Fund management & $\begin{array}{l}\text { All the funds were eventually } \\
\text { pooled together and were } \\
\text { uniformly managed. }\end{array}$ & $\begin{array}{l}\text { The fund of URRBMI were } \\
\text { uniformly managed but } \\
\text { were separated from UEBMI. }\end{array}$ & $\begin{array}{l}\text { The fund of three schemes were } \\
\text { separately managed }\end{array}$ \\
\hline Benefit package & $\begin{array}{l}\text { The benefit package was } \\
\text { expanded compared to the } \\
\text { previous schemes and was } \\
\text { unified for all enrollees. }\end{array}$ & $\begin{array}{l}\text { In URRBMI, the benefit } \\
\text { package was expanded } \\
\text { compared to the previous } \\
\text { URBMI and NRCMS and was } \\
\text { unified for urban and } \\
\text { rural residents. }\end{array}$ & UEBMI> URBMI>NRCMS \\
\hline Reimbursement rate & $\begin{array}{l}\text { The reimbursement rare was } \\
\text { higher than previous schemes } \\
\text { and was unified for all enrollees. }\end{array}$ & $\begin{array}{l}\text { In URRBMI, reimbursement } \\
\text { rare was higher than previous } \\
\text { URBMI and NRCMS and was } \\
\text { unified for urban and rural residents. }\end{array}$ & UEBMI> URBMI>NRCMS \\
\hline
\end{tabular}

365 respondents from the integrated area and 77,165 respondents from the non-integrated area were sampled.

\section{Variables definition}

Inpatient service utilization referred to the use of inpatient service in the previous year, which is based on the question "have you been hospitalized in the past year?"

Need factors included sex, age, self-assessed health, chronic conditions and functional limitation etc.

Non-need factors were other socio-economic variables which influenced use of healthcare except need factors, which included socioeconomic status, education, occupation, household income, region, and medical insurance etc.

\section{Analytic approach}

In this study, we used a concentration index (CI) to measure the degree of income-related inequality which was derived from the concentration curve that plots the cumulative health care utilization against the cumulative distribution of population ranked by socioeconomic status such as income. CI was further decomposed to assess the contribution of different factors (need factors and non- need factors) in explaining inequality in inpatient service utilization. The horizontal inequity (HI) index indicated the income-related inequity in health care utilization after standardizing for differences in health need, such as sex, age and health conditions. HI was calculated based on the CI decomposition results. These methods were proposed by Wagstaff $[25,26]$ and extensively used by many researchers [27-34]. The calculation steps were as follows:

\section{Step 1 Standardization of inpatient service utilization}

Three groups of utilizations including actual inpatient service utilization, need-predicted inpatient service utilization, and need-standardized inpatient service utilization were calculated. Actual inpatient service utilization was collected in NHSS. Need-predicted inpatient service utilization was calculated through statistical modeling, aiming to capture variation in utilization predicted only by needs for inpatient service. Need-standardized inpatient service utilization was used to measure the gap between actual inpatient service utilization and need-predicted inpatient service utilization [32]. An indirect 
standardization with probit regression model was used to calculate the distribution of need-standardized inpatient service utilization as it was binary [25].

\section{Step 2 Estimate of CI and its decomposition} [25]:

The CI index is calculated through equation following

$$
\mathrm{CI}=\frac{2}{\mu} \operatorname{cov}(h, r)
$$

Where $h$ is need-standardized inpatient service utilization, $\mu$ is the mean of need-standardized inpatient service utilization, $r$ is the fractional rank of the individual by income.

The $\mathrm{CI}$ is decomposed into contributions of need factors and non-need factors based on probit regression model [31].

$$
y_{i}=\alpha+\sum_{j} \beta_{j}^{m} x_{j i}+\sum_{k} \gamma_{k}^{n} z_{k i}+\varepsilon_{i}
$$

Where $y_{i}$ is the probability of inpatient service utilization; $x_{j i}$ are the need factors; $z_{k i}$ are the non-need factors; $\beta_{j}^{m}$ and $\gamma_{k}^{n}$ are marginal effects of each variable; $\varepsilon_{i}$ is the error term.

\section{Step 3 Calculation of the HI}

$\mathrm{HI}$ is computed by subtracting the contribution of need factors from the CI, reflecting the degree to which inpatient care service is distributed by income after standardizing for differences in health need [26].

$$
\mathrm{HI}=C I_{m}-C I_{n}
$$

Where $C I_{m}$ refers to the $\mathrm{CI}$ of actual inpatient service utilization, $C I_{n}$ refers to the $\mathrm{CI}$ of the need-expected inpatient service utilization.
All analyses were performed in Stata 12.1.

\section{Results}

\section{Description of the survey population}

Both in the pilot integrated area and non-integrated area, the survey population was predominantly 45 years old and above, married and employed. In the pilot integrated area, $27.48 \%$ of respondents were covered by UEBMI, $5.47 \%$ by USBMI, $57.63 \%$ by URRBMI, and $5.86 \%$ covered by mixed-insurance (enrolled in both social medical insurance and commercial medical insurance). While in the non-integrated area, $23.71 \%$ covered by UEBMI, $10.43 \%$ by URBMI, $56.63 \%$ by NRCMS, and $5.88 \%$ covered by mixed-insurance (see Additional file 1).

\section{Distribution of inpatient service utilization across household income quintiles}

Figure 1 showed the inpatient service utilization by household income quintiles. The actual inpatient service utilization reported by the richest group was 1.6 times of the poorest in the pilot integrated area, and 1.7 times in the non-integrated area. It demonstrated a narrower gap of actual inpatient service utilization between the rich and the poor in the pilot integrated area.

The quintile distribution also shows the difference between the actual and need-expected inpatient service utilization. The actual inpatient service utilization by the richest and the second richest group was about 1.31 times and 1.17 times of their need-expected inpatient service utilization in the pilot integrated area, the figure in non-integrated area was 1.32 times and 1.13 times. While the actual inpatient service utilization by the poorest and second poorest group accounted for 63.97 and $93.27 \%$ of their need-expected inpatient service utilization in the pilot integrated area respectively, accounting for 66.91 and $87.69 \%$ in the non-integrated area. It demonstrated that the overall level of overuse inpatient service among the rich in the pilot integrated
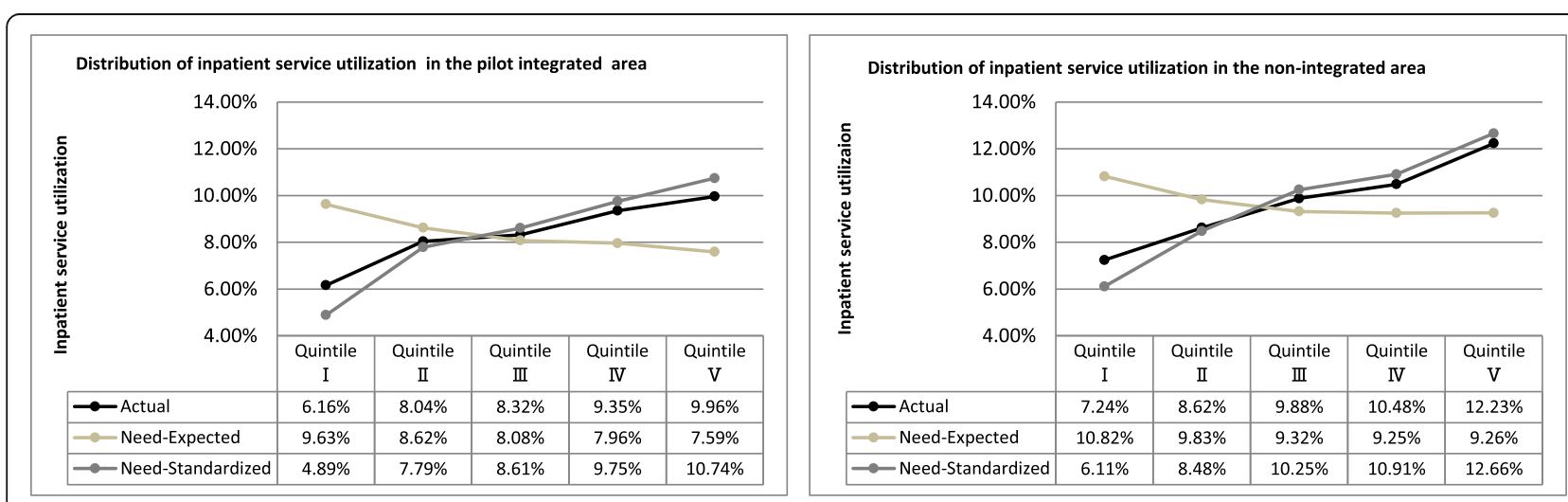

Note: Quintile I was the poorest $20 \%$,and the Quintile V was the richest $20 \%$

Fig. 1 Distribution of inpatient service utilization across household income quintiles 


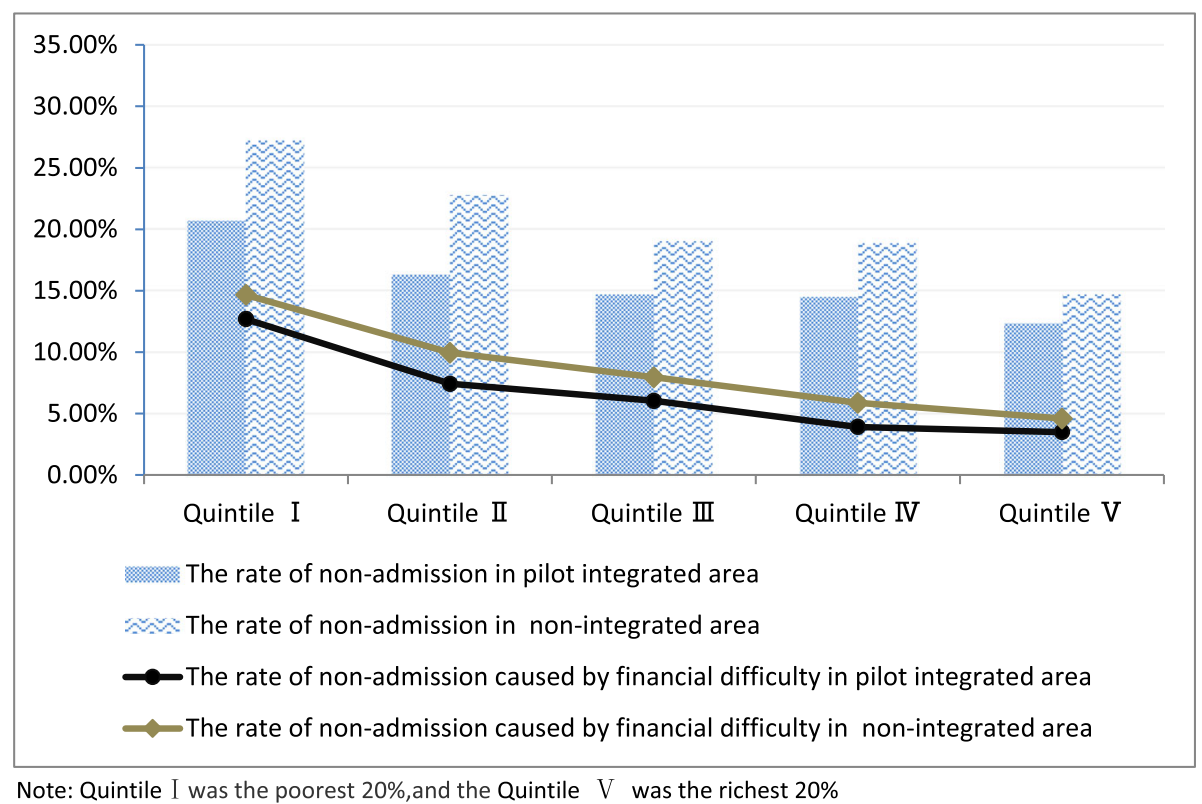

Fig. 2 Non-admission rates across household income quintiles

area was nearly the same as that in non-integrated area, and the underuse was much lower in second poorest group in the pilot integrated area than non-integrated area although the underuse among the poorest group was slightly higher.

\section{Distribution of the non-admission across household income quintiles}

Both in the pilot integrated area and non-integrated area, the no-admission rate (defined as the percentage of patients needing hospitalization but unable to obtain it for various reasons) and the no-admission rate caused by financial difficulty all decreased with rising income quintiles, indicating that the poor group were more likely to forgo needed hospitalization. Nevertheless, the overall no-admission rate and the no-admission rate caused by financial difficulty in the pilot integrated area were all lower than in the non-integrated area among each quintile (average difference was -4.50 and $-1.10 \%$ respectively). More substantial reductions were observed in the poorest and second poorest group (the differences for no-admission rate were $-6.52 \%$ and $-6.47 \%$, for the no-admission rate caused by financial difficulty were 1.97 and $-2.51 \%$ ). Which shown that the pilot integrated area enjoy much reduced no-admission rate and financial barrier (see Fig. 2).
Inequality and inequity in inpatient service utilization

Table 2 shows the results of the $\mathrm{CI}$ and $\mathrm{HI}$ indexes. The actual distribution of inpatient service utilization was pro-rich in the two areas, while the CI was $15.67 \%$ lower in the pilot integrated area $\left(\mathrm{CI}_{\mathrm{M}}=0.0877\right)$ than the nonintegrated area $\left(\mathrm{CI}_{\mathrm{M}}=0.1040\right)$. After need was taken into account, the HI showed even more pro-rich inequity in two areas, however the inequity degree in the pilot integrated area $(\mathrm{HI}=0.0984)$ was $13.23 \%$ lower than non-integrated area $(\mathrm{HI}=0.1134)$. This indicated the inequity degree of inpatient service utilization was reduced in the pilot integrated area.

\section{Decomposition of inequality in inpatient service utilization}

Table 3 shows the results of the decomposition analysis, including each determinant's marginal effect and $\mathrm{CI}_{\mathrm{k}}$ and contribution to $\mathrm{CI}$.

The marginal effect denotes the association between the determinants and the inpatient service utilization. A positive marginal effect means that that factor promoted utilization, and vice versa. Both in the pilot integrated area and non-integrated area, medical insurance (regardless of type) can significantly increase the inpatient service utilization compared to the uninsured group. The UEBMI and mixed-insurance are two of most important

Table $2 \mathrm{Cl}$ and $\mathrm{HI}$ index of inpatient utilization

\begin{tabular}{llll}
\hline & $\mathrm{Cl}_{\mathrm{M}}($ Actual) & $\mathrm{Cl}_{\mathrm{N}}($ Need-Expected) & HI (Need-Standardized) \\
\hline Pilot integrated area & $0.0877^{*}$ & $-0.0107^{*}$ & $0.0984^{*}$ \\
Non-integrated area & $0.1040^{*}$ & $-0.0094^{*}$ & $0.1134^{*}$ \\
\hline
\end{tabular}


Table 3 Decomposition of inequality in inpatient service utilization

\begin{tabular}{|c|c|c|c|c|c|c|}
\hline & \multicolumn{3}{|c|}{ Pilot integrated area } & \multicolumn{3}{|c|}{ Non-integrated area } \\
\hline & $\begin{array}{l}\text { Marginal effect } \\
\left(\beta_{k}\right)\end{array}$ & $C l_{k}$ & $\begin{array}{l}\text { Contribution to } \mathrm{Cl} \\
\text { (\%) }\end{array}$ & $\begin{array}{l}\text { Marginal effect } \\
\left(\beta_{k}\right)\end{array}$ & $C l_{k}$ & $\begin{array}{l}\text { Contribution } \\
\text { to } \mathrm{Cl} \\
(\%) \\
\end{array}$ \\
\hline \multicolumn{7}{|l|}{ Sex and Age } \\
\hline \multicolumn{7}{|l|}{ Male } \\
\hline \multicolumn{7}{|l|}{ 15-24(reference) } \\
\hline $25-34$ & $-0.033^{* *}$ & 0.063 & $-2.00 \%$ & $-0.026^{* *}$ & -0.010 & $0.16 \%$ \\
\hline $35-44$ & $-0.026^{* *}$ & 0.073 & $-2.20 \%$ & -0.009 & 0.076 & $-0.56 \%$ \\
\hline $45-54$ & $-0.017^{*}$ & 0.043 & $-0.93 \%$ & -.0003 & 0.053 & $-0.02 \%$ \\
\hline $55-64$ & -0.006 & -0.071 & $0.62 \%$ & $0.028^{* *}$ & -0.065 & $-1.78 \%$ \\
\hline $65-$ & $0.019^{*}$ & -0.106 & $-2.49 \%$ & $0.058^{* *}$ & -0.065 & $-3.43 \%$ \\
\hline \multicolumn{7}{|l|}{ Female } \\
\hline $15-24$ & $0.109^{* *}$ & 0.008 & $0.64 \%$ & $0.160^{* *}$ & -0.010 & $-0.78 \%$ \\
\hline $25-34$ & $0.082^{* *}$ & 0.101 & $8.57 \%$ & $0.119^{* *}$ & 0.028 & $2.28 \%$ \\
\hline $35-44$ & -0.011 & 0.078 & $-1.05 \%$ & 0.012 & 0.096 & $1.07 \%$ \\
\hline $45-54$ & -0.013 & 0.022 & $-0.38 \%$ & 0.009 & 0.042 & $0.41 \%$ \\
\hline $55-64$ & -0.008 & -0.046 & $0.51 \%$ & $0.026^{* *}$ & -0.060 & $-1.61 \%$ \\
\hline $65-$ & 0.015 & -0.124 & $-2.35 \%$ & $0.053^{* *}$ & -0.064 & $-3.08 \%$ \\
\hline \multicolumn{7}{|l|}{ Chronic disease } \\
\hline Yes & $0.066^{* *}$ & 0.021 & $4.67 \%$ & $0.095^{* *}$ & 0.035 & $7.76 \%$ \\
\hline \multicolumn{7}{|l|}{ No (reference) } \\
\hline \multicolumn{7}{|c|}{ Limitation of daily activities } \\
\hline Yes & $0.060^{* *}$ & -0.126 & $-4.95 \%$ & $0.041^{* *}$ & -0.124 & $-2.64 \%$ \\
\hline \multicolumn{7}{|l|}{ No (reference) } \\
\hline \multicolumn{7}{|c|}{ Self-assessment health } \\
\hline Very poor & $0.155^{* *}$ & -0.115 & $-0.65 \%$ & $0.113^{* *}$ & -0.038 & $-0.15 \%$ \\
\hline Poor & $0.099^{* *}$ & -0.116 & $-2.35 \%$ & $0.124^{* *}$ & -0.079 & $-1.59 \%$ \\
\hline Medium & $0.078^{* *}$ & -0.067 & $-6.55 \%$ & $0.074^{* *}$ & -0.064 & $-5.31 \%$ \\
\hline Good & $0.027^{* *}$ & -0.010 & $-1.35 \%$ & $0.023^{* *}$ & 0.003 & $0.25 \%$ \\
\hline \multicolumn{7}{|c|}{ Very good (reference) } \\
\hline \multicolumn{7}{|l|}{ Education } \\
\hline \multicolumn{7}{|l|}{ Illiterate (reference) } \\
\hline Primary school & 0.004 & -0.083 & $-2.74 \%$ & 0.006 & -0.086 & $-2.77 \%$ \\
\hline Secondary school & -0.06 & 0.138 & $-2.17 \%$ & -0.002 & 0.179 & $-0.69 \%$ \\
\hline College and above & $-0.015^{* *}$ & 0.389 & $-10.81 \%$ & -0.008 & 0.442 & $-4.02 \%$ \\
\hline \multicolumn{7}{|l|}{ Occupation status } \\
\hline \multicolumn{7}{|c|}{ Unemployment (reference) } \\
\hline Student & $-0.055^{* *}$ & 0.059 & $-2.09 \%$ & $-0.066^{* *}$ & 0.150 & $-4.13 \%$ \\
\hline Peasant & -0.004 & -0.296 & $4.21 \%$ & 0.004 & -0.201 & $-3.13 \%$ \\
\hline Worker & $-0.026^{* *}$ & 0.100 & $-3.44 \%$ & $-0.015^{* *}$ & 0.189 & $-1.70 \%$ \\
\hline Business & $-0.031^{* *}$ & 0.181 & $-9.75 \%$ & $-0.023^{* *}$ & 0.200 & $-4.54 \%$ \\
\hline Manager & $-0.027^{* *}$ & 0.293 & $-22.35 \%$ & $-0.016^{* *}$ & 0.351 & $-9.71 \%$ \\
\hline Other & $-0.017^{* *}$ & 0.052 & $-1.16 \%$ & $-0.017^{* *}$ & 0.062 & $-0.93 \%$ \\
\hline
\end{tabular}


Table 3 Decomposition of inequality in inpatient service utilization (Continued)

\begin{tabular}{ll} 
Pilot integrated area & \\
\hline $\begin{array}{l}\text { Marginal effect } \quad \mathrm{Cl}_{\mathrm{k}} \\
\left(\beta_{\mathrm{k}}\right)\end{array}$ & $\begin{array}{l}\text { Contribution to } \mathrm{Cl} \\
(\%)\end{array}$
\end{tabular}

Non-integrated area

Marginal effect

$\left(\beta_{k}\right)$

Contribution

o Cl

(\%)

Marital status

Other (reference)

Married

$0.021^{* *}$

0.015

$3.32 \%$

$0.022^{* *}$

0.014

$2.39 \%$

Household income

Quintile I (reference)

Quintile ॥

$0.033^{* *}$

$0.046^{* *}$

$-0.400$

$-36.32 \%$

0.000

$0.04 \%$

Quintile III

Quintile IV

$0.059^{* *}$

0.401

$65.21 \%$

$0.075^{* *}$

0.801

$162.78 \%$

Medical insurance

UEBMI

$0.040^{* *}$

0.248

$37.50 \%$

URBMI

NRCMS

USBMI

$0.029^{* *}$

$0.027^{* *}$

URRBMI

$0.046^{* *}$

0.277

$-0.175$

0.269

Mixed-insurance

Uninsured and other (reference)

Distance to the nearest health facilities

$<1 \mathrm{~km}$ (reference)

$1-4 \mathrm{~km}$

$0.008^{* *}$

$-0.061$

$-2.56 \%$

$-0.122-0.82 \%$

$0.008^{* *}$

$0.028^{* *}$

$-0.400$

$-22.00 \%$

$0.048^{* *}$

0.000

$0.02 \%$

$0.059^{* *}$

0.400

$47.01 \%$

$0.081^{* *}$

0.800

$128.84 \%$

$\geq 5 \mathrm{~km}$

$0.019^{* *}$

$0.046^{* *}$

$-0.101$

$-2.77 \%$

$0.030^{* *}$

0.355

$25.39 \%$

$0.017^{*}$

0.043

$0.74 \%$

$0.014^{*}$

$-0.184$

$-14.17 \%$

Time to the nearest health facilities

$<15$ min (reference)

$15-29 \mathrm{~min}$

$-0.003$

$-0.063$

$0.47 \%$

$-0.004$

$-0.067$

$0.54 \%$

$\geq 30 \mathrm{~min}$

$-0.005$

$-0.265$

$0.90 \%$

$-0.004$

$-0.288$

$0.77 \%$

Preferred health facilities

Primary facilities (reference)

Non - primary facilities

0.004

0.223

$3.00 \%$

$0.006^{*}$

0.321

$3.63 \%$

Residence

Urban (reference)

Rural

$0.005^{*}$

$-0.196$

$-6.52 \%$

$0.013^{* *}$

$-0.192$

$-12.69 \%$

Region

Eastern

$$
-0.029^{* *}
$$

Middle

$-0.014^{* *}$

0.059

$-13.05 \%$

$-0.135$

$3.13 \%$

$-0.038^{* *}$

$-0.013^{* *}$

0.087

$-10.12 \%$

Western (reference)

Quintile I was the poorest $20 \%$,and the Quintile V was the richest $20 \%$

Note: $p<0.05 ;{ }^{* *} p<0.01$

factors that significantly increased the inpatient service utilization in the two areas. In addition, the role in increasing inpatient service utilization played by USBMI and URRBMI in the pilot integrated area was higher than URBMI and NRCMS in the non-integrated area.
The $\mathrm{CI}_{\mathrm{k}}$ was employed to describe how each determinant was distributed (range from $-1 \sim+1$ ) over the factor of wealth. With regard to the medical insurance type, the URRBMI $\left(\mathrm{CI}_{\mathrm{k}}=-0.175\right)$ and $\operatorname{NRCMS}\left(\mathrm{CI}_{\mathrm{k}}=-\right.$ 0.184 ) were more concentrated among the poor, while 
the USBMI, UEBMI, URBMI, and mixed-insurance were more concentrated among the rich.

The contribution to CI describes each determinant's role in inequality. A positive value implies the determinant increased inequality, and vice versa. In both areas, household income accounted for most of the inequalities (162.78 and $128.84 \%$ for the highest quintile in the pilot integrated area and non-integrated area respectively, it is also true for the second highest quintile groups). While in the pilot integrated area, URRBMI has a pro-poor contribution $(-37.49 \%)$, meaning it played a positive role in reducing inequity by enhancing more inpatient service utilization among poor population. But the other insurance including USBMI and mixed-insurance all contributed from 6.08 to $37.51 \%$, especially UEBMI contribute $37.51 \%$ to the pro-rich inequity. Moreover, chronic disease made a pro-rich contribution in the pilot integrated area (4.67\%) and non-integrated area (7.76\%), while remaining need factors made pro-poor contributions. In addition, rural area $(-6.52$ and $-12.69 \%)$ and eastern region $(-13.05$ and $-10.12 \%)$ had pro-poor contributions that achieving better performance in reducing inequality.

\section{Discussion}

Medical insurance integration reform is one of the key strategies addressing inequity issues caused by a fragmented health system in China. This study compares the pilot integrated area and non-integrated area by employing nationally representative data, and provides powerful evidence of the effectiveness of integration reform in achieving the primary goal of reducing inequity. It also provides a comprehensive view of the combined role of medical insurance with other demographic and socioeconomic factors through a decomposition analysis.

The study reveals a mixed picture in terms of the distribution of inpatient service utilization and how insurance integration influences the degree of inequality. Through comparisons, we found the gap of inpatient service utilization between the rich and the poor was narrower in the pilot integrated area than in the non-integrated area (1.61 times vs 1.69 times). Whilst the nonadmission rate and the non-admission rate caused by financial difficulty were all lower in the pilot integrated area than in the non-integrated area across each household income quintile (average differences were-4.50 and $-1.10 \%$ respectively), the reduced gaps were even larger in the poorest and second poorest group (the differences for no-admission rate were -6.52 and $-6.47 \%$, for the no-admission rate caused by financial difficulty were -1.97 and $-2.51 \%$ ), which indicates that the pilot integrated area enjoyed much reduced no-admission and financial barriers. In addition, the pro-rich equity of inpatient service utilization in the pilot integrated area was
$13.23 \%$ lower than in the non-integrated area. Further, decomposition results show that the URRBMI made the greatest contribution in reducing the inequality $(-37.49 \%)$ in the pilot integrated area although other insurance schemes increased the inequality. These findings to some extent revealed the positive impact of integration reform on reducing inequity in inpatient service utilization.

Integration reform could reduce inpatient service utilization inequity for several reasons. First, it connects different targeted populations regardless of their identity, occupation, and district [14]. That was essential to narrow the insurance benefit gaps and reduce the inequity in healthcare use. Second, for integrated insurance, the level of the benefit package and reimbursement rate was standardized and all increased, which was crucial to provide equitable financial protection to all beneficiaries. Third, risk pooling was increased after integration; for instance, the pooling level of URRBMI which merged the URBMI and NRCMS (previously mainly run at county level) was upgraded to the municipal level. The elevated funding pool will definitely increase the ability of integrated insurance funds to protect against risks [35], which may lead to more equitable access to inpatient health services.

Despite these encouraging results, inpatient service utilization was still pro-rich, and the poorest group still had some inpatient health service needs that were not met. Furthermore, in the decomposition analysis, we found the role played by URRBMI in reducing inequality could not counteract the role played by income or the presence of other insurance types (especially UEBMI) in increasing inequality. These results could be explained in two ways. One is in the imperfect design of the integration reform itself. The financing of integrated URRBMI was similar to that of NRCMS and URBMI (a flat rate contributed by individual and government), and despite increases in premiums, the financing ability of URRBMI has not improved markedly. In fact, the financing level of UEBMI was still nearly 10 times higher than URRBMI [36, 37]. The disparity in financing eventually led to the disparity in reimbursement levels, we found the average actual reimbursement rate of UEBMI was $66.8 \%$ while the URRMBI was $49.8 \%$ in 2013 (see Additional file 2). Thus, URRBMI did equalize the financing and reimbursement level between urban and rural residents and indeed provided more reimbursement for the poor than the rich (actual reimbursement rate range from $57.6 \%$ for the poorest to $44.6 \%$ for the richest), but the gap between it and UEBMI persists. The other reason why the URRBMI could not eliminate inequality was due to its stepwise implementation process. Many pilots are still in the first step of integrating the administration system, insurance agencies and funds, in order to reduce 
the resistance to reform and to reach the policy aim more easily [10]. In some piloted areas, the insurance fund still operates and is managed independently instead of being integrated into a uniform risk pool; this hinders the attainment of equity [20,38]. Furthermore, most pilots provide two or three levels of premium - a higher level of premium means higher reimbursement and more subsidies [39]. But problems emerge. On the one hand, the arrangement of differential compensation based on the capacity to pay the premiums might transfer existing inequity from different insurance schemes into inequity within the integrated scheme. On the other hand, in a voluntary enrollment context, adverse selection may occur which goes against the financial sustainability of the insurance scheme [40].

Obstacles also emerged due to the negative role played by UEBMI in increasing inequity. Although the premium level of UEBMI was higher on average, the disparity of financing levels was outstanding among different areas. It could partly explain the contradictory results in the pilot integrated area: despite much reduced inequity level a pro-rich tendency persisted. The UEBMI contributed $37.50 \%$ to increase the inpatient service utilization inequality in the pilot integrated area. To overcome this issue more thoroughly, a better choice for China would be to merge all existing medical insurance into one scheme-USBMI, that was regarded as the ultimate goal of integration [39]. USBMI could achieve the equity goal through covering all enrollees by a single medical insurance scheme, since the uniformed and expanded fund pooling could increase the anti-risk ability of insurance funds [35]. Our results show the effect of USBMI on increasing inequality (contribution $=6.07 \%$ ) was significantly lower than the existing UEBMI scheme no matter whether we examined the pilot integrated area (contribution $=37.50 \%$ ) or non-integrated area (contribution = 25.39\%). Nevertheless, due to the requirement for much higher level of premiums, greater government subsidies, a better fund management capacity and information system, USBMI currently is only piloted in a few highly developed areas, and not expanded nationally. Despite rapid socio-economic development in China, the income gap between the rich and the poor is widening; the income Gini coefficient is consistently higher than 0.47 since 2003 [41]. Although the benefits package in integrated insurance was provided equally to all enrollees, medical cost affordability remains different due to different household income [42]. This actually led to a gap in the ability to pay for health services between the rich and the poor and eventually caused inequity in access to healthcare. In this study, household income itself contributed 191.71 and $153.87 \%$ to the total inequalities in the pilot integrated area and the non-integrated area. Meanwhile, more than $12 \%$ of the poorest respondents had forgone hospitalization due to financial difficulty while the figure of the richest respondents was less than $5 \%$. Due to insufficient assistance for the low income group by the existing social insurance and welfare policies, healthcare utilization equity cannot be achieved by integration reform itself, but requires a concerted multisectoral action [43].

Owing to the combined effort of medical insurance and other socioeconomic factors, urban-rural and regional disparities in healthcare have been reduced to some extent. This study shows that residing in the eastern region of the country reduced the inequality by $13.05 \%$ in the pilot integrated area, which was higher than it in the non-integrated area (10.12\%). One possible explanation is that most integrated pilots were concentrated in the eastern region with the combined effect of developing both the economy and integration which have reinforced each other, leading to a reduction in inequality in this region. But for residents of rural areas, their inequality was reduced by $6.52 \%$ in the pilot integrated area which was much smaller than in the non-integrated area $(12.69 \%)$. This might be partly explained by the fact that the URRBMI allowed rural residents to approach expensive urban health services, which thus reduced inpatient services use in the pilot integrated area.

An interesting finding of our study is that, among all the need factors, only the presence of chronic diseases drives inequality in inpatient service utilization. Such a phenomenon can be explained by the fact that chronic diseases are more concentrated among the rich; therefore, they used more inpatient services than the poor. The number of chronic disease patients in China is around 300 million [44] and chronic diseases account for approximate $90 \%$ of total deaths [45], posing a profound challenge for China's healthcare system. The current medical insurance system, whether integrated or not, generally implements inpatient treatment-oriented benefits packages, neglecting prevention and outpatient services. Such arrangements easily lead to delayed treatment among the poor. Although many integrated pilots provide outpatient chronic disease packages, the number of conditions covered is usually limited $8 \sim 15$ [46]. A shift to primary health care and a broader benefit package covering chronic disease management and treatment should be incorporated into future integration reform.

There were three limitations to the study. First, this was a cross-sectional study so the causal relationship between integration reform and measured factors could not be established. Second, the changes and effectiveness caused by insurance integration reform cannot be fully measured and demonstrated because this study only investigates the earlier stage of the pilot areas while the policy effect of integration reform usually takes longer to be fully revealed. Third, although the selected pilot 
integrated area and non-integrated area are from the same province or other provinces with similar socioeconomic levels to control the influence of socioeconomic factor, there still might be other socioeconomic factors that confound our results. However, this study provides rare and valuable policy evidence to evaluate the ongoing large scale medical insurance integration reform in China, through comparative analyses and quantitatively measuring the reduction in inequities resulting from integration reform and other influencing factors. It suggests options for more targeted policy interventions to address persistent problems.

\section{Conclusion}

Integration reform played a positive role in reducing inequality in inpatient service utilization. However, inequality still exists, particularly among the poorer population. Improvements can be made. We offer some policy implications for China's integration reform. First, against the backdrop of huge social, economic, geographical disparity in China, the implementation of nationwide uniform medical insurance scheme like USBMI is not likely to be completed within the short term. To reduce resistance to integration reform, URRBMI might be a more feasible and appropriate policy choice for China's next stage of insurance reform. Second, to reduce the gap between URRBMI and UEBMI, governments at different levels should widen financial support and increase funding levels. Third, more attention should be directed to further improving the design of URRBMI, which could include providing greater government subsidies and increasing its share of the premiums, to gradually eliminate the existing two-level premium structure. Fourth, more targeted policies for the poor are needed, including reducing out-of-pocket medical costs and facilitating and expanding family physician contract programs to improve their access to healthcare. Fifth, increasing the coverage of outpatient service and providing chronic disease-related preventive services packages at the primary health care facilities could reduce the overuse among the rich and underuse among the poor, so as to improve equitable access to inpatient care. In addition, it should be clearly noted that the integration reform alone is unlikely to eliminate inequity in inpatient service utilization, coordinated inter-government strategies aimed to reduce socioeconomic inequity in income and social welfare are also needed.

\section{Additional files}

Additional file 1: Description of the survey population. (DOCX $22 \mathrm{~kb}$ )

Additional file 2: The actual reimbursement rate for inpatient service of different medical insurance scheme (\%). (DOCX 16 kb)

\section{Abbreviations}

Cl: Concentration index; HI: Horizontal inequity index; NRCMS: The New Rural Cooperative Medical Scheme; SBMI: Social Basic Medical Insurance; UEBMI: Urban Employee Basic Medical Insurance; UHC: Universal health coverage; URBMI: Urban Resident Basic Medical Insurance; URRBMI: UrbanRural Residents Basic Medical Insurance; USBMI: Uniform Social Basic Medical Insurance

\section{Acknowledgments}

We acknowledge Centre of Health Statistics and Information, National Health Commission of the People's Republic of China.

\section{Authors' contributions}

$M M Z, B H L, L H S, Q H W$ and $Y H H$ designed the study; MMZ, BHL and LHS analyzed and interpreted the data and drafted the original manuscript. CL ZK and LBL contributed to drafted introduction and method. LL, NN and MLJ contributed to the contextualization of the study. QHW, YHH and ZC revised the manuscript. MMZ, BHL and LHS contributed equally to this work. All authors have read and approved the final manuscript for publication.

\section{Funding}

This work was supported by National Natural Science Foundation of China $(71333003,71573068)$. The funders played no role in the design of the study and collection, analysis, and interpretation of data and in writing the manuscript.

\section{Availability of data and materials}

The data that support the findings of this study are available from Centre of Health Statistics and Information, National Health Commission of the People's Republic of China, through its confidential data center, which were used under license for the current study, and thus are not available to the public. Requests for access to the data should be directed to Centre of Health Statistics and Information, National Health Commission of the People's Republic of China.

\section{Ethics approval and consent to participate}

The NHSS was organized and administered by the National Health Commission of the People's Republic of China. The institutional review board of the Chinese National Bureau of Statistics provided review and ethics approval of the survey. All respondents were read a statement that explained the purpose of the survey and provided verbal informed consent before interview.

\section{Consent for publication \\ Not applicable.}

\section{Competing interests}

The authors declare that they have no competing interests.

\section{Author details}

${ }^{1}$ Department of Social Medicine, School of Health Management, Harbin Medical University, 157 Baojian Road, Nangang District, Harbin 150086, Heilongjiang, China. ${ }^{2}$ Department of Health Management, School of Public Health, Nantong University, 9 Seyuan Road, Chongchuan District, Nantong 226019, Jiangsu, China. ${ }^{3}$ Department of Health Policy and Management College of Public Health, University of Georgia, Athens, GA 30602, USA.

${ }^{4}$ School of Economics, Faculty of Humanities and Social Sciences, University of Nottingham Ningbo, 199 Taikang East Road, Ningbo, Zhejiang 315100, China.

Received: 22 October 2018 Accepted: 28 August 2019 Published online: 10 September 2019

\section{References}

1. Stronks K, Louise GJ. Should equity in health be target number 1? Eur J Pub Health. 1993;3(2):104-11.

2. Murray CJL, Frenk J. A framework for assessing performance of health system. Bull World Health Organ. 2000;78:717-31.

3. Ottersen T, Norheim OF, Chitah BM, Cookson R, Daniels N, Defaye FB, Eyal N, Flores W, Gosseries A, Hausman D, et al. Making fair choices on the path 
to universal health coverage. Bull World Health Organ. 2014;92:389. https:// doi.org/10.2471/BLT.14.139139.

4. de Looper M, Lafortune G. "Measuring Disparities in Health Status and in Access and Use of Health Care in OECD Countries", OECD Health Working Papers, No. 43. Paris: OECD Publishing; 2009. https://doi.org/10.1787/22574 8084267.

5. Mclntyre D, Ranson MK, Aulakh BK, Honda A. Promoting universal financial protection: evidence from seven low- and middle-income countries on factors facilitating or hindering progress. Health Res Policy Syst. 2013;11:36.

6. Dunlop S, Coyte PC, Mclsaac W. Socio-economic status and the utilisation of physicians' services: results from the Canadian National Population Health Survey. Soc Sci Med. 2000;5(11):123-33.

7. Devaux M. Income-related inequalities and inequities in health care services utilisation in 18 selected OECD countries. Eur J Health Econ. 2015;16(1):2133.

8. Chomi EN, Mujinja PGM, Enemark U, Hansen KS, Kiwara A. Health care seeking behaviour and utilisation in a multiple health insurance system: does insurance affiliation matter. Int J Equity Health. 2014;13(1):25.

9. Mcintyre D, Garshong B, Mtei G, Meheus F, Thiede M, Akazili J, Ally M, Aikins M, Mulligan J, Goudge J. Beyond fragmentation and towards universal coverage: insights from Ghana, South Africa and the United Republic of Tanzania. Bull World Health Organ. 2008:86(11):871-6.

10. Meng Q, Fang H, Liu X, Yuan B, Xu J. Consolidating the social health insurance schemes in China: towards an equitable and efficient health system. Lancet. 2015;386(10002):1484-92.

11. Castroleal F, Dayton J, Demery L, Mehra K. Public spending on health care in Africa: do the poor benefit? Bull World Health Organ. 2000;78(1):66-74.

12. Li Y, Malik V, Hu FB. Health insurance in China: after declining in the 1990s, coverage rates rebounded to near-universal levels by 2011. Health Aff (Millwood). 2017;36(8):1452-60

13. He AJ, Wu S. Towards universal health coverage via social health insurance in China: systemic fragmentation, reform imperatives, and policy alternatives. Appl Health Econ Health Policy. 2017;15(6):707-16.

14. Wang HQ, Liu ZH, Zhang YZ, Luo ZJ. Integration of current identity-based district-varied health insurance schemes in China: implications and challenges. Front Med. 2012;6(1):79-84.

15. Zhang X, Wu Q, Shao Y, Fu W, Liu G. Socioeconomic inequities in health care utilization in China. Asia-Pac J Public He. 2015;27(4):429-38.

16. Li Y. A comparative study of urban and rural integration Medicare typical pattern-take Dongguan, Zhuhai, and Zhanjiang City as an example. Health Econ Res. 2014;06:17-22.

17. Chen $\mathrm{H}$. Zhongshan medical insurance has already met the requirements. Zhongshan Daily. 2009-10-19(A01). http://kns.cnki.net/kcms/detail/Detail. aspx?dbname $=C$ CNDHIS\&filename $=$ ZSRB20091019A010\& $\mathrm{v}=$ \&filetitle $=\% E 4 \%$ B8\%AD\%E5\%B1\%B1\%E5\%8C\%BB\%E4\%BF\%9D\%E5\%85\%88\%E8\%A1\%8C\% E6\%97\%A9\%E5\%B7\%B2\%E8\%BE\%BE\%Е5\%88\%B0\%Е8\%A6\%81\%E6\%B1\%82.

18. Shan L, Zhao M, Ning N, et al. Dissatisfaction with current integration reforms of health insurance schemes in China: are they a success and what matters? Health Policy Plan. 2018:33(3):345-54.

19. The Central People's Government, China. Opinions of the CPC Central Committee and the State Council on deepening the reform of the medical and health system.2009.

20. Zhang D. Analysis on the challenges and countermeasures faced by the integration of medical insurance for urban and rural residents. Assets Finances in Adm Institution. 2017:09:35-6.

21. Yang $X$. The urban and rural residents' medical insurance integration pilot in Hubei province: practice, effect and difficulty. Hubei Soc Sci. 2017;07:59-63.

22. Wu C, Li Y, Shen C, Shen Y, Dai T. Research on the integrating the urbanrural resident medical insurance system: taking Jiaxing of Zhejiang as an example. Chin Health Econ. 2016;05:41-4.

23. Xue W, Zhou X, Zhang S. Integration Objectives and Strategies Based on Urban and Rural Medical Insurance System. J Hunan Agric Univ. 2015;03:98-102.

24. Wang $X$, Zheng $A$, He $X$, Jiang $H$. Integration of rural and urban healthcare insurance schemes in China: an empirical research. BMC Health Servi Res. 2014;14:142

25. Wagstaff A, Paci P, van Doorslaer E. On the measurement of inequalities in health. Soc Sci Med. 1991;33(5):545-57.

26. Wagstaff $\mathrm{A}$, van Doorslaer $\mathrm{E}$, Watanabe $\mathrm{N}$. On decomposing the causes of health sector inequalities with an application to malnutrition inequalities in Vietnam. J Econ. 2003;112(1):207-23.
27. van Doorslaer E, Masseria C. "Income-Related Inequality in the Use of Medical Care in 21 OECD Countries", OECD Health Working Papers, No. 14 Paris: OECD Publishing; 2004. https://doi.org/10.1787/687501760705.

28. Sözmen K, Ünal B. Explaining inequalities in health care utilization among Turkish adults: findings from health survey 2008. Health Policy. 2016;120(1): $100-10$.

29. Zhou Z, Su Y, Gao J, Campbell B, Zhu Z, Xu L, Zhang Y. Assessing equity of healthcare utilization in rural China: results from nationally representative surveys from 1993 to 2008. Int J Equity Health. 2013;12(1):34.

30. Lu JR, Leung GM, Kwon S, Tin KYK, Van Doorslaer E, O'Donnell O. Horizontal equity in health care utilization evidence from three high-income Asian economies. Soc Sci Med. 2007;64(1):199-212.

31. Van Doorslaer E, Koolman X, Jones AM. Explaining income-related inequalities in doctor utilisation in Europe: a decomposition approach. Health Econ. 2004;13(7):629-47.

32. Xie $X, W u Q$, Hao $Y$, et al. Identifying determinants of socioeconomic inequality in health service utilization among patients with chronic noncommunicable diseases in China. PLoS One. 2014;9(6):e100231.

33. Chen Z, Roy K. Calculating concentration index with repetitive values of indicators of economic welfare. J Health Econ. 2009;28(1):169-75.

34. Chen Z, Roy K, Gotway CC. Evaluation of variance estimators for the concentration and health achievement indices: a Monte Carlo simulation. Health Econ. 2012;21(11):1375-81.

35. Carrin G, James C. Reaching universal coverage via social health insurance: key design features in the transition period. Geneva: World Health Organization; 2004. https://www.who.int/health_financing/issues/en/ reaching_universal_dp_04_2.pdf

36. Zhu K, Zhang L, Yuan S, Zhang X, Zhang Z. Health financing and integration of urban and rural residents' basic medical insurance systems in China. I Int J Equity Health. 2017;16(1):1-p12.

37. National Bureau of Statistics of China. Average wages for urban employee. http://data.stats.gov.cn/easyquery.htm?cn=C01\&zb=A040F\&sj=2016. Accessed 14 Apr 2018.

38. Qiu Y, Yuan T. Integrating urban and rural residents medical insurance systems: observation and consideration. China Health Insurance. 2016;04:157.

39. Zhang $\mathrm{X}, \mathrm{Hu} \mathrm{H}$, Zhang W, Liu R. Analysis of the integration of urban and rural residents health care system by the implementation of 'Multiple level in one medical insurance system. China Health Insurance. 2014;05:15-7.

40. Wang H, Zhang L, Yip W, Hsiao W. Adverse selection in a voluntary rural mutual health care health insurance scheme in China. Soc Sci Med. 2006; 63(5):1236-45

41. Xiujuan $Y$, Zhang J. The influence and countermeasure of the gap between rich and poor on China's social development. Contemporary World and Socialism. 2014;03:184-8.

42. Lei $X$, Cui F. Integrating and improving the basic medical insurance system for urban and rural residents. J Northwest A\&F University (Social Science Edition). 2016:05:1-7.

43. Zere E, Oluwole D, Kirigia JM, Mwikisa CN, Mbeeli T. Inequities in skilled attendance at birth in Namibia: a decomposition analysis. BMC Pregnancy Childbirth. 2011;11:34

44. Souhu Net. The first "blue book of health management" have been published in China. 2018. http://www.sohu.com/a/231598259_258430 Accessed 26 July 2018.

45. National Health Commission of People's Republic of China.lllustration: report on nutrition and chronic diseases of Chinese residents. 2015. http://www. nhfpc.gov.cn/jkj/s5879/201506/4505528e65f3460fb88685081ff158a2.shtml. Accessed 26 July 2018

46. Ning Y. How to protect the chronic disease by medical insurance. Chinese Health. 2017;8:50-5. https://doi.org/10.15973/j.cnki.cn11-3708/d.2017.08.019.

\section{Publisher's Note}

Springer Nature remains neutral with regard to jurisdictional claims in published maps and institutional affiliations. 